\title{
An inter-laboratory comparison of urinary 3-hydroxypropylmercapturic acid measurement demonstrates good reproducibility between laboratories
}

\author{
Emmanuel Minet ${ }^{1 *}$, Graham Errington ${ }^{1}$, Gerhard Scherer ${ }^{2}$, Kirk Newland ${ }^{3}$, Mehran Sharifi ${ }^{4}$, Brian Bailey ${ }^{5}$,
}

Mike McEwan ${ }^{1}$ and Francis Cheung ${ }^{1}$

\begin{abstract}
Background: Biomarkers have been used extensively in clinical studies to assess toxicant exposure in smokers and non-smokers and have recently been used in the evaluation of novel tobacco products. The urinary metabolite 3HPMA, a metabolite of the major tobacco smoke toxicity contributor acrolein, is one example of a biomarker used to measure exposure to tobacco smoke. A number of laboratories have developed liquid chromatography with tandem mass spectrometry (LC-MS/MS) based methods to measure urinary 3-HPMA; however, it is unclear to what extent the data obtained by these different laboratories are comparable.
\end{abstract}

Findings: This report describes an inter-laboratory comparison carried out to evaluate the comparability of 3-HPMA measurement between four laboratories. A common set of spiked and authentic smoker and non-smoker urine samples were used. Each laboratory used their in-house LC-MS/MS method and a common internal standard. A comparison of the repeatability $(' r ')$, reproducibility $(' R ')$, and coefficient of variation for 3-HPMA demonstrated that within-laboratory variation was consistently lower than between-laboratory variation. The average inter-laboratory coefficient of variation was $7 \%$ for fortified urine samples and $16.2 \%$ for authentic urine samples. Together, this represents an inter-laboratory variation of $12.2 \%$.

Conclusion: The results from this first inter-laboratory comparison for the measurement of 3-HPMA in urine demonstrate a reasonably good consensus between laboratories. However, some consistent measurement biases were still observed between laboratories, suggesting that additional work may be required to further reduce the inter-laboratory coefficient of variation.

\section{Background}

Cigarette smoke contains thousands of chemicals, including toxicants, which can be categorized as either gases, semi-volatiles (gas/vapor phase), or particles ("tar" phase) [1]. Machine-measured cigarette yields under the ISO testing regimen do not provide an accurate estimate of human exposure to cigarette smoke toxicants [2]. These limitations have led to the development of methods to quantify biomarkers for specific toxicants in biological fluids such as urine, saliva, and plasma [3].

\footnotetext{
* Correspondence: emmanuel_minet@bat.com

'British American Tobacco, Group Research and Development, Regents Park Road, Southampton, SO15 8TL, UK

Full list of author information is available at the end of the article
}

The gas phase, tobacco smoke toxicant acrolein [CAS:107-02-8] (Figure 1A) has been identified by the World Health Organization (WHO) study group on Tobacco Product Regulation (TobReg) as a major contributor to smoke toxicity [4]. This evaluation was based on the concentration of acrolein in smoke and its toxicity potency factor (cancer and non-cancer), established using various models. 3-hydroxypropylmercapturic acid (3HPMA) is the major urinary metabolite of acrolein (Figure 1B) [5], and it can be quantified using LC-MS based methods $[3,5]$.

One critical element in the measurement and interpretation of biomarker data (including 3-HPMA) is the comparability in method analysis between different
C Biomed Central

(c) 2011 Minet et al; licensee BioMed Central Ltd. This is an open access article distributed under the terms of the Creative Commons Attribution License (http://creativecommons.org/licenses/by/2.0), which permits unrestricted use, distribution, and reproduction in any medium, provided the original work is properly cited. 


\section{A. Acrolein \\ average mass $=\mathbf{5 6 . 0 6} \mathrm{Da}$<smiles>C=CC=O</smiles>

B. 3-HРMA

monoisotopic mass $=221.07 \mathrm{Da}$

HO-

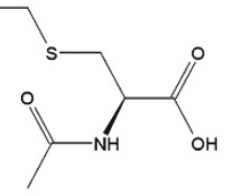

C. 3-НРМА- ${ }^{13} \mathrm{C}_{3^{-}} 15 \mathrm{~N}$

monoisotopic mass $=225.08 \mathrm{Da}$

HO

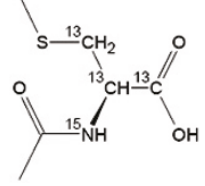

Figure 1 Chemical structure of acrolein (A), 3-HPMA (B), and 3HPMA- ${ }^{13} \mathrm{C}_{3}-{ }^{15} \mathrm{~N}$ (C). 3 -HPMA and $3-\mathrm{HPMA}-{ }^{13} \mathrm{C}_{3}{ }^{-15} \mathrm{~N}$ molecular weights are also indicated. laboratories, which can use different methodologies. For instance, a study conducted by Biber and colleagues on a common set of urinary and plasma samples comparing nicotine and cotinine data from eleven laboratories concluded that individual values could vary significantly between laboratories [6]. In a more recent study, Bernert and colleagues showed that good measurement reproducibility for cotinine in a common set of samples could be achieved between six laboratories, when a standardized HPLC-UV method was used [7].

In this study we tested the reproducibility of 3-HPMA measurement between four laboratories using their inhouse method and a common set of fortified and authentic urine samples. Each laboratory used a common reference compound and the internal standard 3HPMA- ${ }^{13} \mathrm{C}_{3^{-}}{ }^{15} \mathrm{~N}$.

\section{Material and methods \\ Reagents and samples}

Synthetic 3-HPMA (reference compound, Figure 1B) and 3-HPMA- ${ }^{13} \mathrm{C}_{3}-{ }^{15} \mathrm{~N}$ (internal standard, Figure 1C) were obtained from AptoChem (Montreal, Canada). 3HPMA- ${ }^{13} \mathrm{C}_{3}{ }^{15} \mathrm{~N}$ was ordered as a custom synthesis and the same lot was used by each laboratory. 3-HPMA- $\mathrm{d}_{3}$ was supplied by Toronto Research Chemicals (North York, Canada). Pooled non-smoker urine samples were supplied fortified with 3-HPMA by RECIPE Chemicals (Munich, Germany). Four concentrations of synthetic 3HPMA were used: unspiked (background $\approx 30-50 \mathrm{ng} /$

Table 1 Analytical method characteristics

\begin{tabular}{|c|c|c|c|c|}
\hline Laboratories & 1 & 2 & 3 & 4 \\
\hline Method & LC-ESI-MS/MS & LC-ESI-MS/MS & LC-ESI-MS/MS & LC-ESI-MS/MS \\
\hline mode & positive & negative & positive & negative \\
\hline SPE (column) & Phenomenex Strata-X & Isolute ENV+ & Waters OASIS & Waters OASIS \\
\hline SPE recovery (\%) & 74 & 68 & 75 & 78 \\
\hline HPLC column (make) & Waters Xterra MS C18 & Waters HILIC-Silica & Waters Acquity Phenyl & Thermo BioBasic AX \\
\hline HPLC column (size) & $50 \times 2.1 \mathrm{~mm}, 2.5 \mu \mathrm{m}$ & $150 \times 2.1 \mathrm{~mm}, 3 \mu \mathrm{m}$ & $100 \times 2.1 \mathrm{~mm}, 1.7 \mu \mathrm{m}$ & $50 \times 3 \mathrm{~mm}, 5 \mu \mathrm{m}$ \\
\hline Quantifier ion (mass) & m/z $222-163$ & m/z $220-89$ & m/z $222-117$ & m/z $220-91$ \\
\hline Qualifier ion (mass) & m/z $222-117$ & m/z $220-91$ & & \\
\hline precision intra-day (\%) & 1.1 to 5.9 & 1.4 to 8.6 & 1.1 to 1.5 & 1.2 to 6.5 \\
\hline precision inter-day (\%) ${ }^{a}$ & 5.1 to 5.3 & 3.3 to 7 & 1.7 to 3.9 & 3.3 to 7.5 \\
\hline accuracy (\%) & 93.2 to 102 & 83.9 to 102 & 97.6 to 102 & 96.8 to 101 \\
\hline LOD $(\mathrm{ng} / \mathrm{ml})$ & 2.21 & $N D^{d}$ & ND & $N D^{d}$ \\
\hline LOQ $(\mathrm{ng} / \mathrm{ml})$ & 7 & 25 & $50^{f}$ & $35^{f}$ \\
\hline Linearity (ng/ml) & 7 to 5400 & 25 to 10000 & 50 to 5000 & 35 to 5000 \\
\hline Matrix effect (\%) & ND & 7.4 to 17 & -1.7 to 19.6 & -5.5 to 6.3 \\
\hline
\end{tabular}

avalues represent the precision range obtained for low, medium, and high concentrations at the time the methods were developed, except for Lab 1 where only low and high concentrations were tested.

based on calibration standards.

'LOD was an estimate based on spiked water, water being used as the SPE solvent.

${ }^{\mathrm{d}}$ Not determined

eLOQ was established in spiked water, water being used as SPE solvent.

${ }^{f}$ Matrices used were either diluted non-smoker urine or non-smoker urine with very low 3-HPMA background. 
$\mathrm{ml}), 400 \mathrm{ng} / \mathrm{ml}, 1200 \mathrm{ng} / \mathrm{ml}$, and $3600 \mathrm{ng} / \mathrm{ml}$ 3-HPMA. Prior to distribution, the samples were quantified using one of the participating laboratories (Lab 2) in order to ensure the quality of the preparation. The samples were then portioned into 5-ml-aliquots, lyophilized and shipped to the laboratories in triplicates of each sample $(3 \times 4$ vials with lyophilized urine). The laboratories were advised to reconstitute the samples with $5 \mathrm{ml}$ water.

Five authentic urine samples, covering a 3-HPMA concentration range which reflects typical levels in non-smokers to heavy smokers, were aliquoted in triplicates and sent to the participating laboratories ( $3 \times 5$ vials). The lyophilized non-smoker urine samples were supplied by RECIPE $^{\circledR}$ (Munich, Germany), a supplier of samples used for quality assurance testing. The smoker samples were obtained as part of a biomarker study conducted previously by BAT. The corresponding study protocol and informed consent forms were approved by the Ethics Committee of the Bayerische landesarztekammer Munich, Germany (v. 18.02.2008), which contained a provision for revisiting the samples for the purpose of biomarker method development. The clinical study was conducted in accordance with the World Medical Association Declaration of Helsinki (World Medical Association, 2004) and International Conference on Harmonisation (ICH) Guidelines for Good Clinical Practice (GCP) (International Conference on Harmonization, 1996).

\section{Analytical procedure}

The samples were labelled with a code number and randomized prior to distribution. $10 \mathrm{mg}$ of each reference compound and the internal standard were dispatched as a dried powder. Samples were received in one batch by each laboratory in September 2009, and all analyses were completed by November 2009. A summary of the analytical methods is given in Table 1, which is based on the performance of QC samples measured prior to the initiation of the study. All four laboratories used their inhouse protocol, which included a solid phase extraction step and analysis by LC-ESI-MS/MS. The methods were validated according to FDA guidelines.

\section{Statistical analysis}

Basic statistical analysis was carried out with MINITAB v15.1. Individual value plots were produced to test interlaboratory variation of 3-HPMA concentrations. A nonparametric Wilcoxon paired t-test was performed to compare preliminary test analyses conducted with different internal standards. Analysis of covariance was used to compare the analytical methods at the four laboratories using the same internal standard (3-HPMA- $\left.{ }^{13} \mathrm{C}_{3^{-}}{ }^{15} \mathrm{~N}\right)$. Precision statistics, as defined in ISO 5725-2 [8], were used as a measure of random errors, and expressed as
Table 2 All urinary 3-HPMA data in $\mathbf{n g} / \mathrm{ml}$

\begin{tabular}{|c|c|c|c|c|c|c|}
\hline & & \multirow[b]{2}{*}{ Samples } & \multicolumn{4}{|c|}{ 3-HPMA (ng/ml) } \\
\hline & & & Lab1 & $L a b 2$ & Lab3 & Lab4 \\
\hline \multirow[t]{3}{*}{1} & a & pooled $\mathrm{NS}^{\mathrm{a}}$ urine & 40.6 & 31.9 & $<\mathrm{LOQ}^{\mathrm{b}}$ & $<\mathrm{LOQ}$ \\
\hline & b & pooled NS urine & 29.8 & 30.8 & $<\mathrm{LOQ}$ & $<\mathrm{LOQ}$ \\
\hline & C & pooled NS urine & 40.0 & 30.7 & $<\mathrm{LOQ}$ & $<\mathrm{LOQ}$ \\
\hline \multirow[t]{3}{*}{2} & a & fortified NS urine & 466 & 492 & 396 & 405 \\
\hline & b & fortified NS urine & 402 & 470 & 400 & 403 \\
\hline & C & fortified NS urine & 431 & 471 & 401 & 402 \\
\hline \multirow[t]{3}{*}{3} & a & fortified NS urine & 1302 & 1340 & 1180 & 1070 \\
\hline & b & fortified NS urine & 1230 & 1270 & 1160 & 1140 \\
\hline & C & fortified NS urine & 1140 & 1340 & 1150 & 1090 \\
\hline \multirow[t]{3}{*}{4} & a & fortified NS urine & 3624 & 3780 & 3470 & 3220 \\
\hline & b & fortified NS urine & 3714 & 3820 & 3420 & 3210 \\
\hline & C & fortified NS urine & 3504 & 3970 & 3370 & 3240 \\
\hline \multirow[t]{3}{*}{5} & a & NS urine & 39.8 & 48.3 & $<\mathrm{LOQ}$ & $<\mathrm{LOQ}$ \\
\hline & b & NS urine & 48.2 & 46.1 & $<\mathrm{LOQ}$ & 36.6 \\
\hline & C & NS urine & 62.4 & 46.9 & $<\mathrm{LOQ}$ & 35.1 \\
\hline \multirow[t]{3}{*}{6} & a & smoker urine & 371 & 376 & 269 & 321 \\
\hline & b & smoker urine & 376 & 382 & 294 & 269 \\
\hline & C & smoker urine & 371 & 370 & 300 & 258 \\
\hline \multirow[t]{3}{*}{7} & $\mathrm{a}$ & smoker urine & 870 & 842 & 613 & 556 \\
\hline & b & smoker urine & 960 & 874 & 673 & 659 \\
\hline & C & smoker urine & 840 & 830 & 721 & 619 \\
\hline \multirow[t]{3}{*}{8} & a & smoker urine & 1080 & 1200 & 862 & 969 \\
\hline & b & smoker urine & 1122 & 1160 & 925 & 914 \\
\hline & C & smoker urine & 1044 & 1180 & 878 & 929 \\
\hline \multirow[t]{3}{*}{9} & a & smoker urine & 1482 & 1390 & 1200 & 1100 \\
\hline & b & smoker urine & 1296 & 1370 & 1210 & 1130 \\
\hline & C & smoker urine & 1260 & 1390 & 1100 & 894 \\
\hline
\end{tabular}

Samples are numbered from 1 to 9 . Samples 1 non-smoker urine, samples 2-4 $=$ fortified samples, and samples 5-9 = authentic urine samples. Each sample was aliquoted in triplicates labeled $\mathrm{a}, \mathrm{b}$, and $\mathrm{c}$.

${ }^{\mathrm{a} N S}$ : non smokers

${ }^{b}<$ LOQ: below limit of quantification

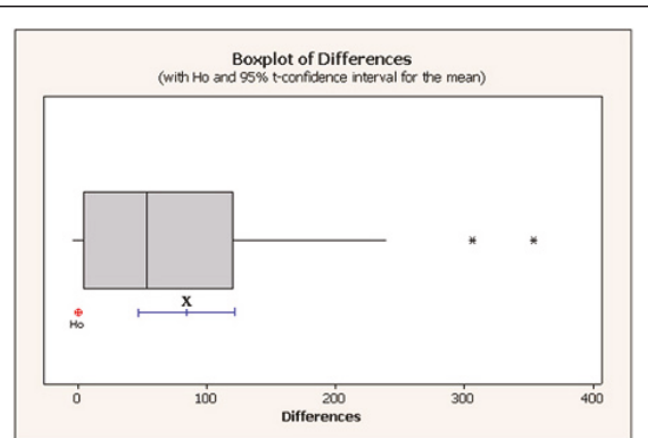

Figure 2 Boxplot of non-parametric differences between 3HPMA measured in all samples using 3-HPMA-d $\mathrm{d}_{3}$ and 3-HPMA${ }^{13} \mathrm{C}_{3^{-}}{ }^{15} \mathrm{~N}$ internal standards. The hypothesis (Ho) is based on no difference (0) between the 3-HPMA- $d_{3}$ measures minus the 3HPMA- ${ }^{13} \mathrm{C}_{3^{-}}{ }^{15} \mathrm{~N}$ measures. The box plot shows a clear positive difference with $p=0$ based on a Wilcoxon paired t-test with a 95\% confidence interval for the mean difference $(x)$. 
repeatability ('r') and reproducibility ('R'). For the purposes of this study, in which each laboratory used its own method, ' $R$ ' refers to inter-laboratory variation.

\section{Results and discussion}

Data for both fortified and authentic urine, using 3HPMA- ${ }^{13} \mathrm{C}_{3}{ }^{-15} \mathrm{~N}$ as internal standard, were reported by each lab and the corresponding 3-HPMA concentrations $(\mathrm{ng} / \mathrm{ml})$ are shown in Table 2 . In addition, laboratory 1 repeated the measurements using two different internal standards - 3-HPMA- $\mathrm{d}_{3}$ and 3-HPMA- ${ }^{13} \mathrm{C}_{3}{ }^{-15} \mathrm{~N}$ - which were prepared and analyzed on the same day, in order to investigate the potential confounding effects of using different standards under the same analytical conditions. A non-parametric paired $t$-test showed that the use of 3HPMA- $\mathrm{d}_{3}$ gave consistently higher concentrations than 3 -HPMA- ${ }^{13} \mathrm{C}_{3}-{ }^{15} \mathrm{~N}$ (Figure 2), highlighting the importance of standardizing the use of internal standards across each laboratory throughout the study.

A background level of 40 to $60 \mathrm{ng} / \mathrm{ml} \mathrm{3-HPMA}$ was observed in the non-smoker samples selected for this study. This is expected given that acrolein is also the product of lipid peroxidation, fossil fuel combustion, and is found in cooked food [9].

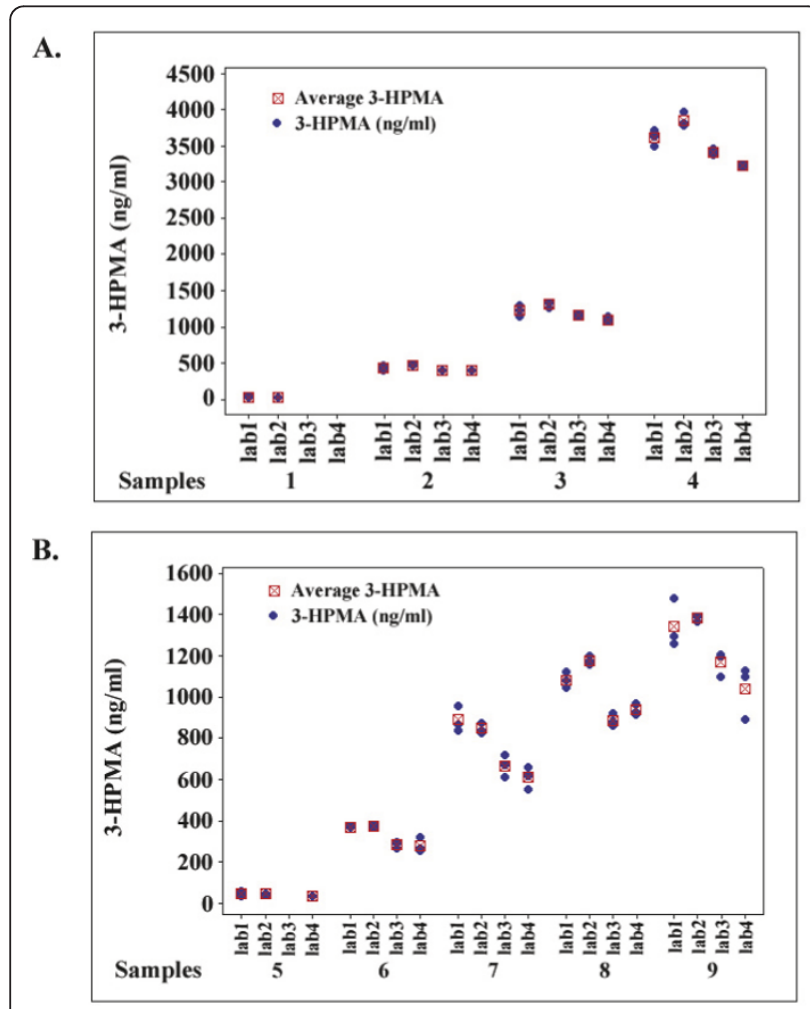

Figure 3 Individual value plots for 3-HPMA (blue circles) (ng/ $\mathrm{ml}$ ). A. Value plot for the fortified samples in four laboratories. B. Value plot for authentic urine samples in four laboratories. Missing values were below the LOQ.
As a quality control check, data from the fortified urine samples (Table 2) were plotted to generate a regression line and the corresponding equation. Using this, the values for the urine samples (Table 2) were recalculated based on the 3-HPMA peak area and the 3-HPMA- ${ }^{13} \mathrm{C}_{3}$ ${ }^{15} \mathrm{~N}$ internal standard. The calculated concentrations were consistent with the reported concentrations from each lab (Additional file 1).

Individual value plots constructed using the sample data indicate a close similarity in the measurements, across the broad range of 3-HPMA concentrations, for all four laboratories using 3-HPMA- ${ }^{13} \mathrm{C}_{3}{ }^{15} \mathrm{~N}$ (Figure 3). However, an analysis of covariance (ANOVA) indicated a significant variation between laboratories still existed (Table 3). A closer fit could be observed between lab 1 and 2 , and between lab 3 and 4 . The coefficients of variation, giving an estimate of the imprecision for repeated measures at different concentration ranges, are also reported in Table 3. The imprecision for each concentration range should be interpreted carefully since the replicate measures were obtained from three aliquots from a

Table 3 One way ANOVA for 3-HPMA vs laboratories (lab1, 2, 3, and 4) for each set of samples

\begin{tabular}{|c|c|c|c|c|c|}
\hline & & $\begin{array}{c}\text { Mean 3-HPMA } \\
\text { (ng/ml) }\end{array}$ & StDev & CoV & $\begin{array}{c}P \text { value (one-way } \\
\text { Anova) }\end{array}$ \\
\hline \multirow{4}{*}{$\begin{array}{c}\text { Sample } \\
1\end{array}$} & lab1 & 36.8 & 6.1 & 16.5 & 0.186 \\
\hline & lab2 & 31.13 & 0.7 & 2.1 & \\
\hline & lab3 & $<\mathrm{LOQ}$ & NA & NA & \\
\hline & lab4 & $<\mathrm{LOQ}$ & NA & NA & \\
\hline \multirow{4}{*}{$\begin{array}{c}\text { Sample } \\
2\end{array}$} & lab1 & 433 & 32.2 & 7.4 & 0.002 \\
\hline & lab2 & 477.7 & 12.4 & 2.6 & \\
\hline & lab3 & 399 & 2.6 & 0.7 & \\
\hline & lab4 & 403.3 & 1.5 & 0.4 & \\
\hline \multirow{4}{*}{$\begin{array}{c}\text { Sample } \\
3\end{array}$} & lab1 & 1224 & 81.2 & 6.6 & 0.004 \\
\hline & lab2 & 1316.7 & 40.4 & 3.1 & \\
\hline & lab3 & 1163.3 & 15.3 & 1.3 & \\
\hline & lab4 & 1100 & 36.1 & 3.3 & \\
\hline \multirow{4}{*}{$\begin{array}{c}\text { Sample } \\
4\end{array}$} & lab1 & 3614 & 105.4 & 2.9 & 0.000 \\
\hline & lab2 & 3856.7 & 100.2 & 2.6 & \\
\hline & lab3 & 3420 & 50 & 1.5 & \\
\hline & lab4 & 3223.3 & 15.3 & 0.5 & \\
\hline \multirow{4}{*}{$\begin{array}{l}\text { Sample } \\
5\end{array}$} & lab1 & 50.1 & 11.4 & 22.8 & 0.182 \\
\hline & lab2 & 47.1 & 1.1 & 2.4 & \\
\hline & lab3 & $<\mathrm{LOQ}$ & NA & NA & \\
\hline & lab4 & 35.8 & 1.1 & 3 & \\
\hline \multirow{3}{*}{$\begin{array}{l}\text { Sample } \\
6\end{array}$} & lab1 & 372.4 & 2.77 & 0.7 & 0.000 \\
\hline & lab2 & 376 & 6 & 1.6 & \\
\hline & lab3 & 287.7 & 16.4 & 5.7 & \\
\hline
\end{tabular}


Table 3 One way ANOVA for 3-HPMA vs laboratories (lab1, 2, 3, and 4) for each set of samples (Continued)

\begin{tabular}{cccccc}
\hline & lab4 & 282.7 & 33.6 & 11.9 & \\
\hline $\begin{array}{c}\text { Sample } \\
\mathbf{7}\end{array}$ & lab1 & 890 & 62.4 & 7 & 0.000 \\
& lab2 & 848.7 & 22.7 & 2.7 & \\
& lab3 & 669 & 54.1 & 8.1 & \\
& lab4 & 611.3 & 51.9 & 8.5 & \\
\hline $\begin{array}{c}\text { Sample } \\
\mathbf{8}\end{array}$ & lab1 & 1082 & 39 & 3.6 & 0.000 \\
& lab2 & 1180 & 20 & 1.7 & \\
& lab3 & 888.3 & 32.7 & 3.7 & \\
& lab4 & 937.3 & 28.4 & 3 & \\
\hline Sample & lab1 & 1346 & 119.1 & 8.85 & 0.006 \\
$\mathbf{9}$ & & & & & \\
& lab2 & 1383.3 & 11.5 & 0.8 & \\
& lab3 & 1170 & 60.8 & 5.2 & \\
& lab4 & 1041.3 & 128.5 & 12.3 &
\end{tabular}

${ }^{9} \mathrm{NA}$ : not applicable, fewer than three data points due to at least one measure $<$ LOQ. single solution rather than a triplicate measure of a unique sample. The fortified samples (samples 2 to 4 ), were used as an internal calibration reference to calculate accuracies (Table 4).

A comparison of the repeatability (' $r$ '), reproducibility (' $R$ '), and coefficient of variation for 3-HPMA demonstrated that within-laboratory variation was consistently lower than between-laboratory variation. The average intra-laboratory $\mathrm{CoV}$ was $5 \%$, while the average interlaboratory $\mathrm{CoV}$ was $12.2 \%$ (Table 5 ). The average interlaboratory coefficient of variation was $7 \%$ for the fortified urine samples and $16.2 \%$ for the authentic urine samples. These results show close comparability with those observed by Biber and colleagues, where samples spiked with cotinine had an inter-laboratory $\mathrm{CoV}$ ranging from 3 to $19 \%$, while a $\mathrm{CoV}$ range of 4 to $59 \%$ was reported for authentic urine samples of smokers [10].

The overall average inter-laboratory coefficient of variation for all samples in this study was $12.2 \%$. A CoV value higher than $10 \%$ might indicate that there is still some room for improvement; however, this seems to be in line

Table 4 Accuracies calculated for each laboratory based on 3-HPMA fortified samples at $400 \mathrm{ng} / \mathrm{ml}$ (samples 2 ), 1200 $\mathrm{ng} / \mathrm{ml}$ (samples 3), and $3600 \mathrm{ng} / \mathrm{ml}$ (samples 4)

\begin{tabular}{ccccc}
\hline & \multicolumn{3}{c}{ Accuracies (\%) } \\
\hline Fortified sample $(\mathbf{n g} / \mathbf{m l})$ & Lab1 & Lab2 & Lab3 & Lab4 \\
\hline $400 \mathrm{ng} / \mathrm{ml}$ & 108 & 119 & 99 & 101 \\
$1200 \mathrm{ng} / \mathrm{ml}$ & 102 & 110 & 97 & 92 \\
$3600 \mathrm{ng} / \mathrm{ml}$ & 100 & 107 & 95 & 90 \\
\hline
\end{tabular}

${ }^{\mathrm{a} A v e r a g e}$ calculated over three independent measures

Table 5 Repeatability, reproducibility, and intra, inter-laboratory coefficient of variation for 3-HPMA between the four participating laboratories

\begin{tabular}{cccccc}
\hline Samples & Mean 3-HPMA $(\mathbf{n g} / \mathbf{m l})^{\boldsymbol{a}}$ & $\boldsymbol{r}^{\boldsymbol{b}}$ & $\boldsymbol{R}^{\boldsymbol{c}}$ & CoV within (\%) $^{\boldsymbol{d}}$ & CoV between (\%) $^{\boldsymbol{e}}$ \\
\hline $\mathbf{1}$ & 34 & 5.8 & 13.9 & 6.1 & $\mathrm{NA}^{\mathrm{f}}$ \\
$\mathbf{2}$ & 428 & 50 & 100.8 & 4.2 & 8.4 \\
$\mathbf{3}$ & 1201 & 142.7 & 261.8 & 4.2 & 7.8 \\
$\mathbf{4}$ & 3528 & 268.4 & 460.3 & 2.7 & 4.7 \\
$\mathbf{5}$ & 45 & 7.6 & 24.2 & 5.9 & $\mathrm{NA}^{f}$ \\
$\mathbf{6}$ & 330 & 54.9 & 138 & 6 & 15 \\
$\mathbf{7}$ & 755 & 143.3 & 363.4 & 6.8 & 17.2 \\
$\mathbf{8}$ & 1021 & 89.1 & 346.4 & 3.1 & 12.1 \\
$\mathbf{9}$ & 1235 & 223.1 & 710.1 & 6.5 & 20.5
\end{tabular}

\footnotetext{
${ }^{\mathrm{b}}$ Reproducibility

${ }^{\text {c }}$ Repeatability

${ }^{d}$ composite intralaboratory coefficient of variation

einter-laboratory coefficient of variation for the four participating laboratories

fNA: not applicable due to data $<$ LOQ
}

${ }^{a}$ Mean of individual 3-HPMA values for all participating laboratories and for the corresponding sample set 
with WHO standardized clinical methods, which in previous studies have reported average inter-laboratory coefficients of variation $(\mathrm{CoV})$ above $10 \%$ [11-13].

The results from this first inter-laboratory comparison for the measurement of 3-HPMA in urine demonstrate a reasonably good consensus between laboratories, with an average $\mathrm{CoV}$ of $12.2 \%$. However, some consistent measurement biases were still observed between laboratories, suggesting that additional work may be required to reduce the inter-laboratory $\mathrm{CoV}$ even further.

\section{Additional material}

Additional file 1: Authentic urine 3-HPMA concentrations recalculated using a calibration curve derived from the urine samples spiked with synthetic 3-HPMA. The 3-HPMA fortified nonsmokers urine samples were used to establish 3-HPMA calibration curves for each laboratory. The concentration of 3-HPMA in authentic smokers urine was back-calculated based on the calibration curve and peak areas. The values were compared with the values obtained by each lab with their own calibration curve.

\section{Abbreviations}

3-HPMA: 3-hydroxypropylmercapturic acid; CoV: coefficient of variation; ESI: electrospray; LC-MS: liquid chromatography-mass spectrometry; r: repeatability; R: reproducibility; TobReg: tobacco product regulation; UV: ultraviolet; WHO: world health organization

\section{Author details}

'British American Tobacco, Group Research and Development, Regents Park Road, Southampton, SO15 8TL, UK. ${ }^{2}$ Analytisch-Biologisches Forschungslabor GmbH, Goethestrasse 20, 80336 Muenchen, Germany. ${ }^{3}$ Celerion, 621 Rose Street, Lincoln, NE 68502, USA. ${ }^{4}$ Labstat International Inc., 262 Manitou Drive, Kitchener, Ontario N2C 1L3, Canada. ${ }^{5}$ Covance Laboratories Ltd, Otley Road, Harrogate, HG3 1PY, UK.

\section{Authors' contributions}

$\mathrm{EM}, \mathrm{MM}, \mathrm{FC}$, and GS designed the study. GS, KN, BB, and MS conducted the sample analyses. GE performed the statistical analysis. EM and FC drafted the manuscript. All authors read and approved the final manuscript. Written informed consent was obtained from the urine donors for publication of this manuscript and accompanying images. A copy of the form was made available for review by the by the Editor-in-Chief of this journal.

\section{Competing interests}

British American Tobacco (BAT) funded and designed the study. The participating laboratories are service providers for Biomarkers analysis and have previously conducted biomarkers analyses for BAT.

Received: 16 November 2010 Accepted: 10 October 2011 Published: 10 October 2011

\section{References}

1. Rogdman A, Perfetti TA: The chemical components of tobacco and tobacco smoke. Baton Rouge, CRC Press; 2008.

2. WHO Scientific Advisory Committee on Tobacco Product Regulation (SacTob): Conclusions and recommendations on health claims derived from ISO/FTC method to measure cigarette yield. World Health Organization Geneva; 2002.

3. Scherer G, Engl J, Urban M, Gilch G, Janket D, Riedel K: Relationship between machine-derived smoke yields and biomarkers in cigarette smokers in Germany. Regul Toxicol Pharmacol 2007, 47:171-183.
4. Burns DM, Dybing E, Gray N, Hecht S, Anderson C, Sanner T, O'Connor R, Djordjevic M, Dresler C, Hainaut P, Jarvis M, Opperhuizen A, Straif K: Mandated lowering of toxicants in cigarette smoke: a description of the World Health Organization TobReg proposal. Tob Control 2008, 17:132-141.

5. Carmella SG, Chen M, Zhang Y, Zhang S, Hatsukami DK, Hecht SS: Quantitation of acrolein-derived (3-hydroxypropyl)mercapturic acid in human urine by liquid chromatography-atmospheric pressure chemical ionization tandem mass spectrometry: effects of cigarette smoking. Chem Res Toxicol 2007, 20:986-990.

6. Biber A, Scherer G, Hoepfner I, Adlkofer F, Heller WD, Haddow JE, Knight GJ: Determination of nicotine and cotinine in human serum and urine: an interlaboratory study. Toxicol Lett 1987, 35:45-52.

7. Bernert JT, Jacob P, Holiday DB, Benowitz NL, Sosnoff CS, Doig MV, Feyerabend C, Aldous KM, Sharifi M, Kellogg MD, Langman L: Interlaboratory comparability of serum cotinine measurements at smoker and nonsmoker concentration levels: a round-robin study. Nicotine Tob Res 2009, 11:1458-1466.

8. ISO 5725-2: Accuracy (trueness and precision) of measurement methods and results: Part 2. Basic method for the determination of repeatability and reproducibility of a standard measurement method. International Organization for Standardization. Geneva, Switzerland; 1994.

9. Stevens JF, Maier CS: Acrolein: sources, metabolism, and biomolecular interactions relevant to human health and disease. Mol Nutr Food Res 2008, 52(1):7-25

10. Biber A, Scherer G, Hoepfner I, Adlkofer F, Heller WD, Haddow JE, Knight GJ: Determination of nicotine and cotinine in human serum and urine: an interlaboratory study. Toxicol Lett 1987, 35:45-52.

11. Coucke W, Devleeschouwer N, Libeer JC, Schiettecatte J, Martin M, Smitz J: Accuracy and reproducibility of automated estradiol-17beta and progesterone assays using native serum samples: results obtained in the Belgian external assessment scheme. Hum Reprod 2007, 22:3204-3209.

12. Siekmann $L$ : Requirements for reference (calibration) laboratories in laboratory medicine. Clin Biochem Rev 2007, 28:149-154.

13. Thorpe SJ, Heath A, Blackmore S, Lee A, Hamilton M, O'broin S, Nelson BC, Pfeiffer C: International Standard for serum vitamin B(12) and serum folate: international collaborative study to evaluate a batch of lyophilised serum for B(12) and folate content. Clin Chem Lab Med 2007, 45:380-386.

doi:10.1186/1756-0500-4-391

Cite this article as: Minet et al: An inter-laboratory comparison of urinary 3-hydroxypropylmercapturic acid measurement demonstrates good reproducibility between laboratories. BMC Research Notes 2011 4:391.

\section{Submit your next manuscript to BioMed Central and take full advantage of:}

- Convenient online submission

- Thorough peer review

- No space constraints or color figure charges

- Immediate publication on acceptance

- Inclusion in PubMed, CAS, Scopus and Google Scholar

- Research which is freely available for redistribution 